\title{
Experiences with improved cookstoves in Southern Africa
}

\author{
Whitney Pailman ${ }^{1}$, Jiska de Groot*1,2, Mike Clifford ${ }^{3}$, Sarah Jewitt ${ }^{4}$, \\ Charlotte Ray ${ }^{3}$ \\ 1 Energy Research Centre, University of Cape Town, Private Bag X3, Rondebosch, South Africa \\ 2 African Climate and Development Initiative, University of Cape Town. Private Bag X3, Rondebosch, South Africa \\ 3. Faculty of Engineering, University of Nottingham, University Park, Nottingham NG7 2RD, UK \\ 4. School of Geography, University of Nottingham, University Park, Nottingham NG7 2RD, UK
}

\begin{abstract}
This study explores user experiences with improved cookstoves, drawing on findings from household surveys conducted in South Africa, Mozambique, Malawi and Zambia. Investigations were conducted on fuel and stove preferences; experiences with improved biomass cookstoves; the rationale for fuel and stovestacking subsequent to the initial uptake of improved biomass cookstoves; and aspirations for energy and fuel use among improved biomass cookstove users. Significant differences were identified in the perceived benefits of improved biomass cookstoves in the four countries and their priorities, with the most important benefits being fuel and cost savings. These would affect the reference frames within which end-users adopt improved biomass cookstoves. Local circumstances and diverse sets of priorities that affect household decisions need to be considered when promoting or rolling out improved cookstove initiatives.
\end{abstract}

Keywords: household energy; cooking fuels; cooking technologies; cooking with biomass; energy ladder; technology uptake; sustained use.

Journal of Energy in Southern Africa 29(4): 13-26

DOI: http://dx.doi.org/10.17159/2413-3051/2018/v29i4a5072

Published by the Energy Research Centre, University of Cape Town ISSN: 2413-3051 http://journals.assaf.org.za/jesa

Sponsored by the Department of Science and Technology

\footnotetext{
* Corresponding author: Tel. (+27) 216503230.

Email: Jiska.degroot@uct.ac.za
} 


\section{Introduction}

The persistent use of solid biomass and inefficient cooking technologies is a pressing societal challenge. Worldwide, an estimated 2.8 billion people do not have access to clean cooking facilities, with the vast majority of those dependent on solid biomass residing in rural areas (International Energy Agency (IEA), 2014). In sub-Saharan Africa alone, it is estimated that 730 million people depend on the traditional use of solid biomass in open fires and inefficient cookstoves (IEA, 2014). The resultant indoor air pollution has adverse health outcomes, primarily respiratory diseases, and is responsible for 3.5 million premature deaths every year (Kaygusuz, 2011; Kurmi et al., 2012; Lim et al., 2012; Gordon et al., 2014; World Health Organisation, 2015). Furthermore, unsustainable harvesting of solid biomass can cause local environmental impacts, such as degradation of forest resources (World Bank, 2011; Global Alliance for Clean Cookstoves (GACC), 2015).

International development agencies and governments promoted the uptake of improved biomass cookstoves (ICSs) to reduce the adverse health and environmental impacts associated with the traditional use of solid biomass. These stoves were designed to be more efficient and reduce indoor air pollution and carbon emissions (Venkataraman, 2010; Bardouille, 2012). The ICS interventions range from marginally improved biomass stoves to advanced biomass stoves; and from stoves using traditional fuels to those using modern fuels such as liquefied petroleum gas (LPG) and electricity. Despite numerous interventions, the desired large-scale uptake and sustained use required to address health and environmental problems effectively have not been achieved (Stockholm Environment Institute (SEI), 2015).

Following a shift from subsidy-led to more market-based approaches to stove dissemination since the 1990s, under the influence of the World Bank's Energy Sector Management Assistance Program (ESMAP), rising prices sometimes slowed the uptake of ICS among low-income users (Simon, 2010; Jewitt \& Raman, 2017). Effectively building markets for ICSs requires an understanding of the customer bases, including their socioeconomic status and cultural factors, as well as energy- and cooking-related behaviour (Simon, 2010). This study focused on the use of the stove and fuels itself.

There was a renewed interest in clean cooking fuels and cookstoves in recent years through the dissemination of clean cookstoves, an agenda strongly pushed by the GACC. This interest was accompanied by increased efforts to understand the complexities influencing the uptake and sustained use of cleaner cooking alternatives published elsewhere (Debbi et al., 2014; Rehfuess et al., 2014; Ruiz-Mercado \& Masera, 2015). These studies con- cluded that achieving sustained uptake of ICS is a complicated process and that a range of factors needs to be considered at household, community, regional and national levels. At the household level, the factors that influence household ICS uptake and fuel choice include socioeconomic (including availability, access, cost, income, awareness, seasonality, education and family size), behavioural and cultural (e.g. taste preferences, lifestyle, food choices), and external ones (e.g., policy and regulatory environment) (Malla \& Timilsina, 2014; Rehfuess et al., 2014). Reflecting this, Debbi et al. (2014:8228) called for 'quantitative evaluations of effectiveness, supplemented with qualitative studies to assess factors affecting uptake, with an equity focus' to allow for future ICS programmes to learn from previous interventions and build on existing studies.

The present paper responds to this call and reports on a qualitative study examining fuel and stove preferences, experiences with ICS, the rationale for fuel and stove stacking after their initial uptake, and aspirations for energy and fuel use. This ex-post facto investigation contributes to filling a significant gap in literature. Rehfuess et al. (2014) found that, despite many stove projects having achieved a reasonable degree of adoption and many studies having explored the success and failure factors of stove interventions, much remains unknown about the sustained use, maintenance and replacement of ICSs. Furthermore, the factors affecting the exclusive or near-exclusive use of ICSs are rarely studied and those influencing adoption are likely to differ from those affecting sustained use (Rehfuess et al., 2014). The user-centred approach adopted in this study is imperative for understanding what end-users value in ICSs and cooking fuels. The objective of this study is, therefore, to add an ICS end-user perspective, which draws on the empirical findings from household surveys conducted in South Africa, Mozambique, Malawi and Zambia. The study also considers more broadly household experiences with stoves that use modern fuels such as natural gas and electricity, as well as user experiences with traditional biomass cookstoves.

\subsection{Improved cookstove adoption and stove stacking}

A critical misconception during the initial wave of cookstove adoption was that large-scale dissemination would automatically lead to widespread adoption; but technological efficiency on its own proved to be an insuffienct driver for adoption (Barnes et al., 1994; Sesan, 2014; Tafadzwa \& Bradnum, 2017). Shankar et al. (2014: 268) cautioned that acquisition should not be considered synonymous with adoption, but rather a first key step toward adoption. They defined adoption as the 'acquisition and substantive use of a technology by a user' and 
highlighted that using modern and efficient technologies correctly and consistently is a key aspect of the adoption of new modern fuels and technologies as well as an essential part of the displacement of traditional fuels and technologies.

Transitioning to clean and modern energy is imperative for alleviating energy poverty. According to the 'traditional' energy ladder theory, as incomes increase, households will switch from traditional fuels such as solid biomass and agricultural residues to modern fuels including electricity and LPG (Smith, 1989; Barnes \& Floor, 1996; Masera, Saatkamp \& Kammen, 2000). Transitional fuels include charcoal and biomass briquettes, which have a higher energy density than firewood and paraffin, which, although considered an upgrade from the traditional use of solid biomass, still pose health and safety risks in terms of toxic fumes, fire hazards and burn-related injuries (Jahan, 2003; Kimenia et al., 2014; Mills, 2016; GACC, 2017; Kimenia \& Van Niekerk, 2017). An implicit assumption of the energy ladder theory is that traditional fuels and technologies would automatically be replaced once households adopt modern fuels and technologies. Empirical evidence, however, suggests that household energy transitions are often more nuanced and that in many instances stacking is more prevalent than direct switching (Masera, Saatkamp \& Kammen, 2000; Hiemstra-van der Horst \& Hovorka, 2008, Van Der Kroon et al., 2015) . Fuel or technology stacking refers to the continued use of traditional fuel and technologies after adopting more modern fuels and technologies (Gordon \& Hyman, 2012).

Ruiz-Mercado and Masera (2015) argued that, while the prevalence of fuel and stove stacking has been acknowledged, the rationale for stacking has not been thoroughly interrogated. It is also alleged that households stack fuel and stoves as a way to improve their energy security (Pachauri \& Spreng, 2012; Ruiz-Mercado \& Masera, 2015). They further argued that fuel stacking allows greater flexibility about fuel choices, enabling households to be more resilient, and less vulnerable to variables such as fluctuating fuel prices, changes in the availability of fuel and unreliable energy services.

For many households that cook with open fires, traditional three-stone cookstoves serve end-uses related to both cooking and non-cooking, including water- and space-heating. ICSs are often not designed to accommodate the heating of large volumes of water, nor do they always adequately meet space-heating requirements (Ruiz-Mercado \& Masera, 2015). Three-stone stoves also serve a variety of social functions and are often embedded in cultural customs and rituals. Most ICSs do not adequately serve these functions (Ruiz-Mercado \& Masera, 2015). According to Shankar et al. (2014), very few studies have been conducted to determine which stoves are used in tandem for particular cooking tasks. This type of information would enable cookstove designs to be fit for purpose and better aligned with end-user cooking requirements. Decisions about cooking fuel and technology purchases are influenced by a complex array of technical, economic and socio-cultural factors such as stove performance, affordability, regional diversity and cooking preferences (Crew 1997; RuizMercado \& Masera, 2015).

The remaining sections are as follows: Section 2 provides the methodology, which is followed by the presentation of the results in Section 3. Section 4 discusses the results of the study in relation to the current literature (presented in Section 1), and some concluding remarks and areas for future research are given in Section 5 .

\section{Methodology}

This study formed part of a larger three-year research project entitled 'Barriers to the uptake of improved cookstoves', which commenced in 2014. The research was funded by the United Kingdom's Departments for International Development and Energy and Climate Change, and the Engineering and Physical Sciences Research Council, with an overall aim to investigate why ICS programmes in southern Africa achieved relatively little market penetration compared with those in East Africa. Purposive sampling was used to identify households in the selected study sites - South Africa, Mozambique, Malawi and Zambia - that had either purchased or received a donated ICS (or had some type of exposure to ICSs). Household lists of ICS users were obtained through the implementing project partners. The sample size was 126 households across the four countries, in urban, rural and periurban areas, as presented in Table 1.

A questionnaire survey was developed, with four sections: (i) socio-demographic information; (ii) current fuel and cookstove preference, use and experience; (iii) improved biomass and traditional stove preference, use and experience; and (iv) barriers to the adoption and sustained use of the ICS. The questionnaire consisted of open and closed questions, which provided a combination of qualitative and quantitative data, and was administered by trained local enumerators. The quantitative data were entered into a software programme for statistical analysis and analysed using descriptive statistics, frequency tables and chi-square tests. The responses to the open questions were entered in Microsoft Excel and coded. The first round of open coding was done to develop standards, e.g., avoid narrowing down themes too early. The themes that emerged were then explored in relation to existing themes in the literature discussed in Section 1. The necessary ethical clearance was obtained through the implementing universities. The enumerators 
Table 1: Geographic locations of survey.

\begin{tabular}{lccc}
\hline Country (aggregate) & District/municipal region & Urban/rural split & No. of households surveyed \\
\hline South Africa (30) & Gauteng & Urban & 9 \\
& Gauteng & Peri-urban & 2 \\
& North West Province & Peri-urban & 10 \\
& Kwa-Zulu Natal & Rural & 9 \\
\hline Mozambique (30) & Maputo City Province & Urban & 9 \\
& Maputo City Province & Peri-urban & 3 \\
& Dondo & Rural & 14 \\
\hline Malawi (30) & Beira & Peri-urban & 4 \\
& Blantyre & Urban & 9 \\
& Zomba & Peri-urban & 10 \\
\hline Zambia (36) & Balaka & Rural & 11 \\
& Lusaka & Urban & 10 \\
& Chibombo & Peri-urban & 10 \\
& Katete & Rural & 16 \\
\hline
\end{tabular}

conducted the survey in accordance with research ethics protocols, informing participants that their participation in the survey was voluntary and their responses anonymous. Suitable acromyms (SA, Mal, Zam, Moz) and associated number were used in brackets to reflect the views of specific respondents in the respective countries.

\section{Results}

\subsection{Cookstove combinations}

To gain more insight into stove combinations used, respondents were asked to list the types of cookstoves in their households and their main uses. Figure 1 shows the percentage of households in each country in possession of a particular type of stove at the time of the survey. The types of stoves included ICSs, ethanol gel, electric, gas and traditional biomass stoves. In Mozambique and Zambia,
$100 \%$ of the respondents had an ICS in their home. In South Africa, and Mozambique, respectively 97 and $80 \%$ of respondents had an ICS. Among South African households sampled, $60 \%$ had electric stoves, while only $13 \%$ had traditional three-stone stoves. Interestingly, these traditional cookstoves were used by respondents in urban and peri-urban settlements in Springs, Gauteng $\left(26.2607^{\circ} \mathrm{S}\right.$, $28.4630^{\circ} \mathrm{E}$ ). In contrast, in Mozambique, $60 \%$ had traditional three-stone stoves or unimproved cookstoves, with the figures for Malawi and Zambia being $73 \%$ and $61 \%$ respectively. Only $23 \%$ in Mozambique, $13 \%$ in Malawi and $22 \%$ in Zambia had electric stoves.

The types of ICSs varied across the study sites, both within and across the countries. In South Africa, the 5 Star, Rocket and Isitofu stoves were used, using biomass briquettes, charcoal and wood

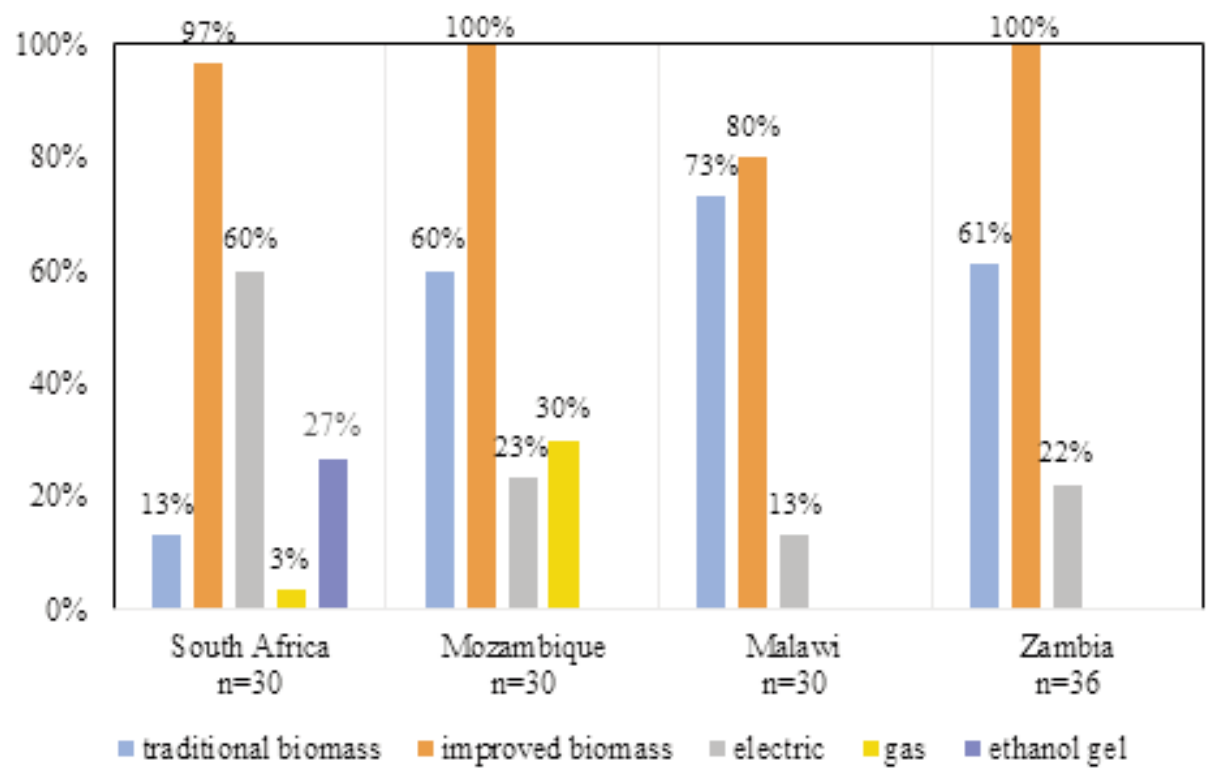

Figure 1: Types of cookstoves in households, where $\mathbf{n}=$ sample size. 


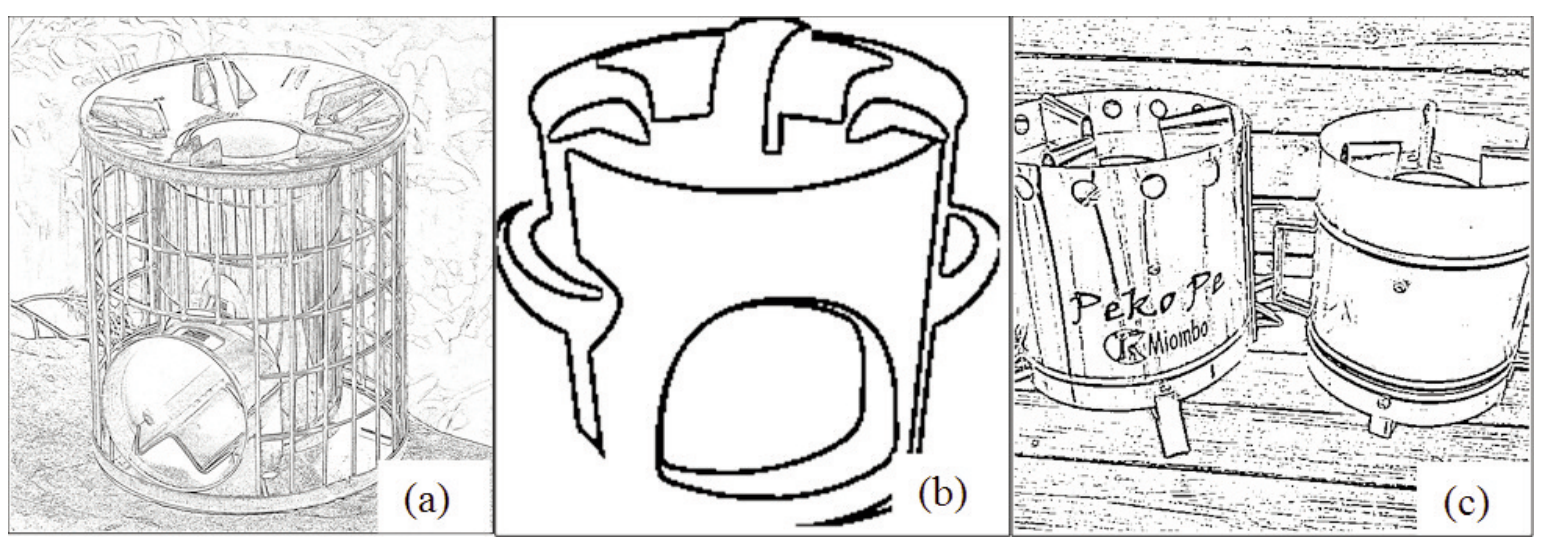

Figure 2: Illustrations of cookstoves, where (a) = Rocket Stove (South Africa), (b) = Kenyan Jiko (Malawi) and (c) = Peko Pe (Zambia).

pellets respectively. In all study sites in Mozambique, the Mbaula charcoal stove was commonly used. In Malawi, the Kenyan Jiko and Chitetezo Mbaula (charcoal and wood stoves) were widely used. Zambian households used the 3RL Rocket stove, Peko Pe and Mud stove, which use wood chips and small logs. Some of these cookstoves are illustrated in Figure 2.

Figure 3 illustrates the 11 cookstove combinations across the four countries indicating the percentage of households using them in each country. It shows that the use of multiple cookstoves or stove-stacking is prevalent, which is consistent with existing studies on the use of multiple stoves within one household in addition to fuel-stacking (Gordon \& Hyman, 2012; Ruiz-Mercado \& Masera, 2015).

The most common cookstove combination among South African respondents was ICS and electric $(47 \%)$. Households with this combination used both stoves primarily for cooking, while some also used their ICS for space-heating. Seasonality and affordability also served as a rationale for multiple stove use. For example, one South African respondent used their improved biomass stove in winter for cooking and heating to save on electricity costs and their electric stove in summer. Another commented: 'This household prefers a Rocket stove as it is used as a heater during winter. It is good for
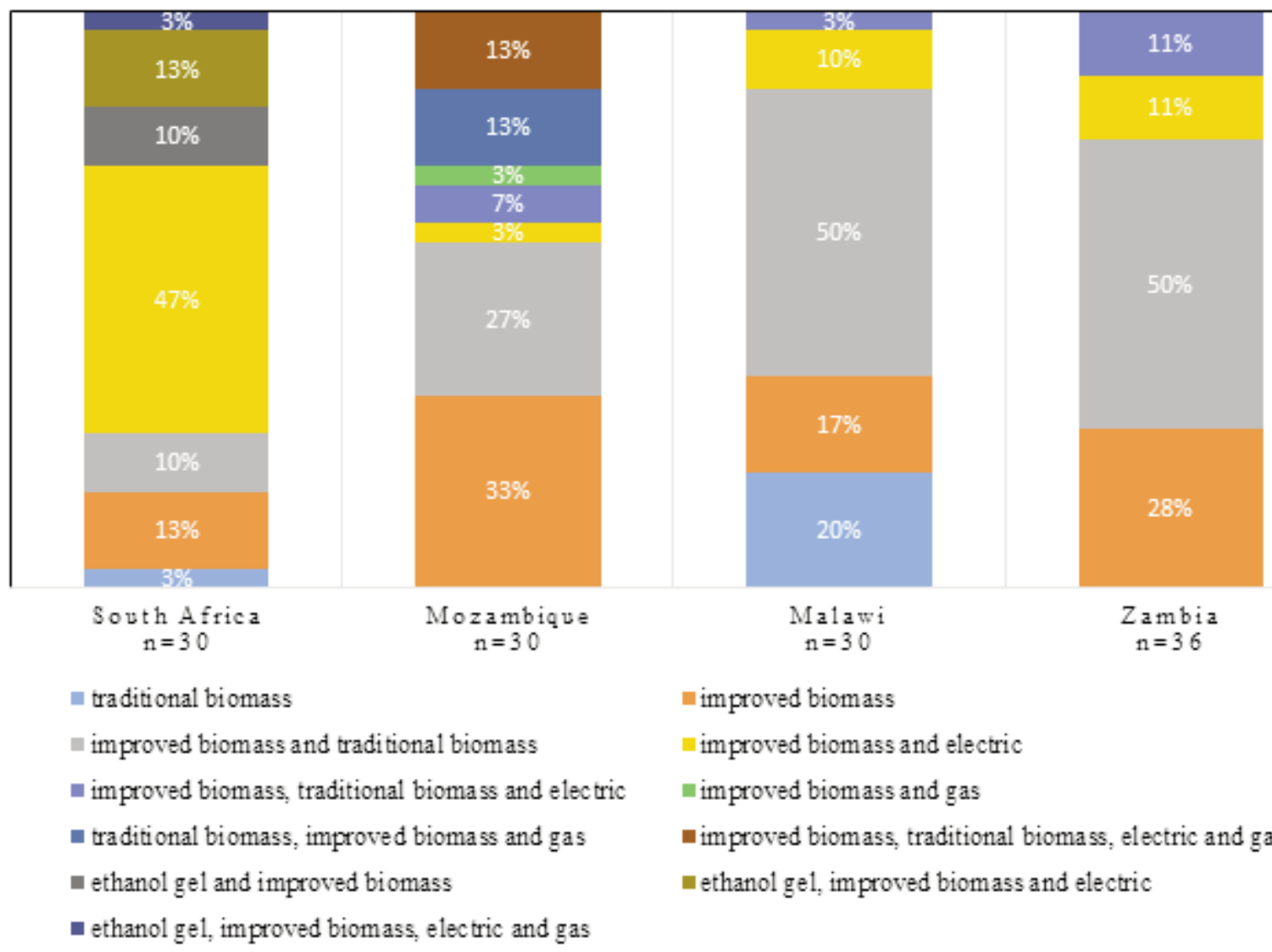

improved biomass

improved biomass and electric

improved biomass and gas

- improved biomass, traditional biomass, electric and gas

w ethanol gel, improved biomass and electric

Figure 3: Cookstove combinations and percentage uses per country, where $\mathrm{n}=$ sample size. 
cooking beetroot and potatoes. An electric stove is used on weekends' [SA 15].

The exclusive use of ICSs was reported by $13 \%$ of South African respondents, $33 \%$ of Mozambican, $17 \%$ of Malawian and $28 \%$ of Zambian. Mozambique had the largest number that only used an ICS. In Malawi and Zambia, 50\% had both improved biomass and traditional biomass stoves. Respondents with this combination primarily used both stoves for cooking, while some used the traditional 'three-stone' stove for water-heating. Seasonality and affordability also affected multiple stove use. One respondent from Malawi commented, 'We mostly use the three-stone as we don't have money for charcoal' [Mal 11]. Another respondent said they use their ICS 'daily during the rainy season' [Mal 30]. The availability of local fuels also affected stove use. One respondent with improved biomass and traditional biomass stoves used the traditional one more frequently because firewood was readily available [Mal 25].

One respondent in Zambia reported that the traditional Mbaula was used in the preparing the traditional staple food nsima (a colloquial name for a thick maize meal porridge dish prepared in most Southern African countries), while the ICS was simultaneously used to prepare the relish (beans) and dried fish [Zam 36]. Another respondent from the same study site, who had the same type of ICS, reported that that the Mbaula stove was used to prepare water for bathing, while the ICS was used to prepare nsima and relish [Zam 34]. In Malawi, a respondent indicated that they used their Chitetezo Mbaula (an ICS), electric stove and traditional stove for cooking, baking and water-heating respectively [Mal 27]. It can therefore be inferrered that there are similarities and differences in how the stove combinations were put to work. Furthermore, there were nuances in cooking practices within and across geographical regions and socio-cultural contexts; and preferences were determined by each household.

More than $70 \%$ of the respondents across the four countries reported that they used their ICS daily. However, nearly $60 \%$ of the respondents in Malawi and Zambia still used a traditional cookstove daily, while $33 \%$ and $36 \%$ in Malawi and Zambia respectively indicated that they used their traditional cookstoves occasionally, as shown in Figure 5.

\subsection{Current and aspirational fuels for cooking}

The primary fuels used for cooking across the four countries included electricity, biomass briquettes, charcoal, firewood, natural gas (in Mozambique) and ethanol gel. Figure 6 shows that solid biomass fuels (both transitional and traditional) dominated the primary fuel mix for cooking. In South Africa, $33 \%$ of respondents used biomass briquettes for cooking, $27 \%$ used charcoal and $17 \%$ used wood. In Mozambique, charcoal (43\%) and wood (27\%) were the main biomass cooking fuels used. In Malawi, 55\% used charcoal and $41 \%$ used firewood as the main cooking fuel, while in Zambia $72 \%$ used firewood.

The prominent use of biomass fuels in all four countries was driven by varying factors. Some South African respondents who primarily cooked with biomass briquettes or pellets mentioned their relative affordability in comparison with electricity. The view of one respondent who cooked with pellets was that 'the difficulty arises because the electricity bill can get very high and sometimes it cannot be paid' [SA 10]. In Malawi and Zambia, the local availability of charcoal and firewood, respectively, were the main reasons cited. One respondent from

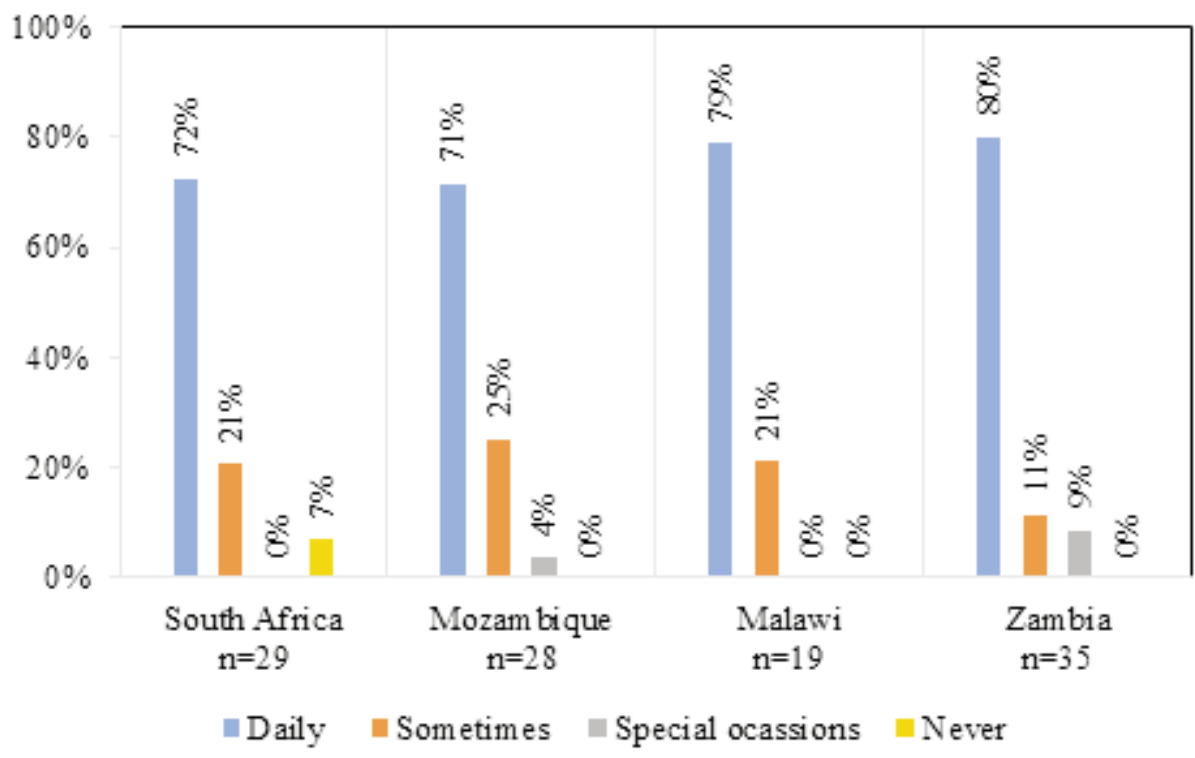

Figure 4: Frequency of use of ICSs, where $n$ = sample size. 


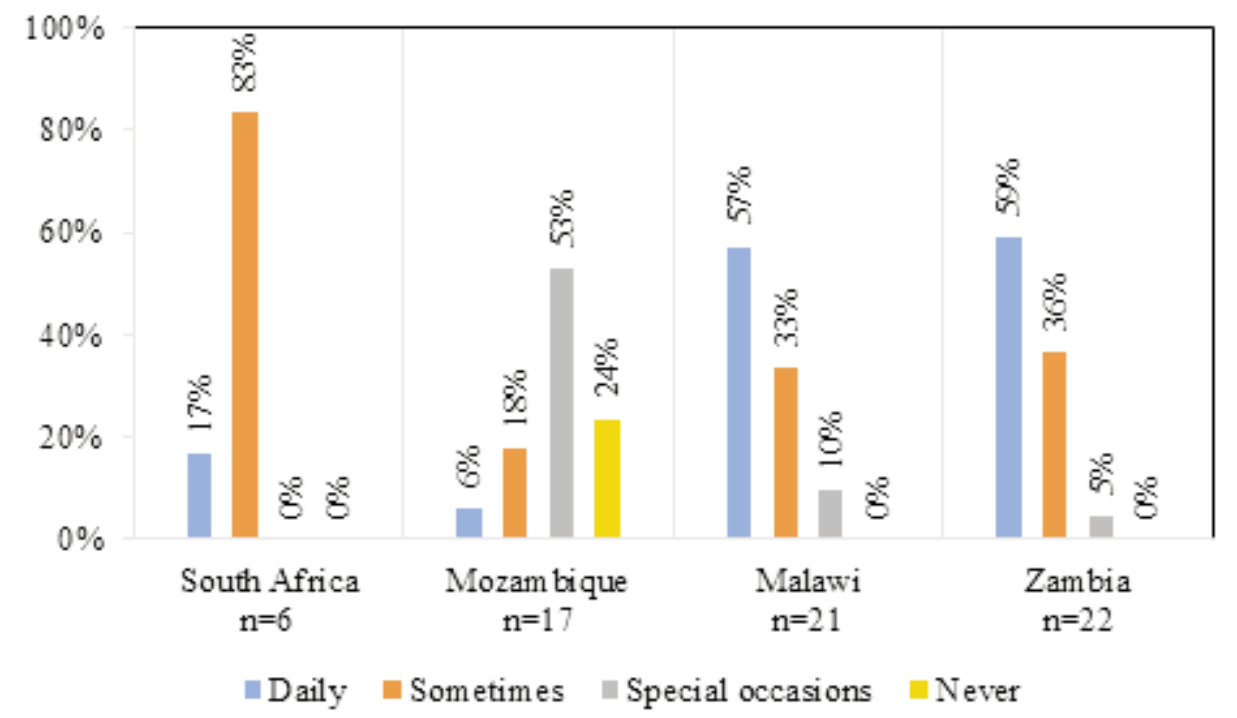

Figure 5: Frequency of use of traditional biomass cookstove, where $\mathbf{n}=$ sample size.

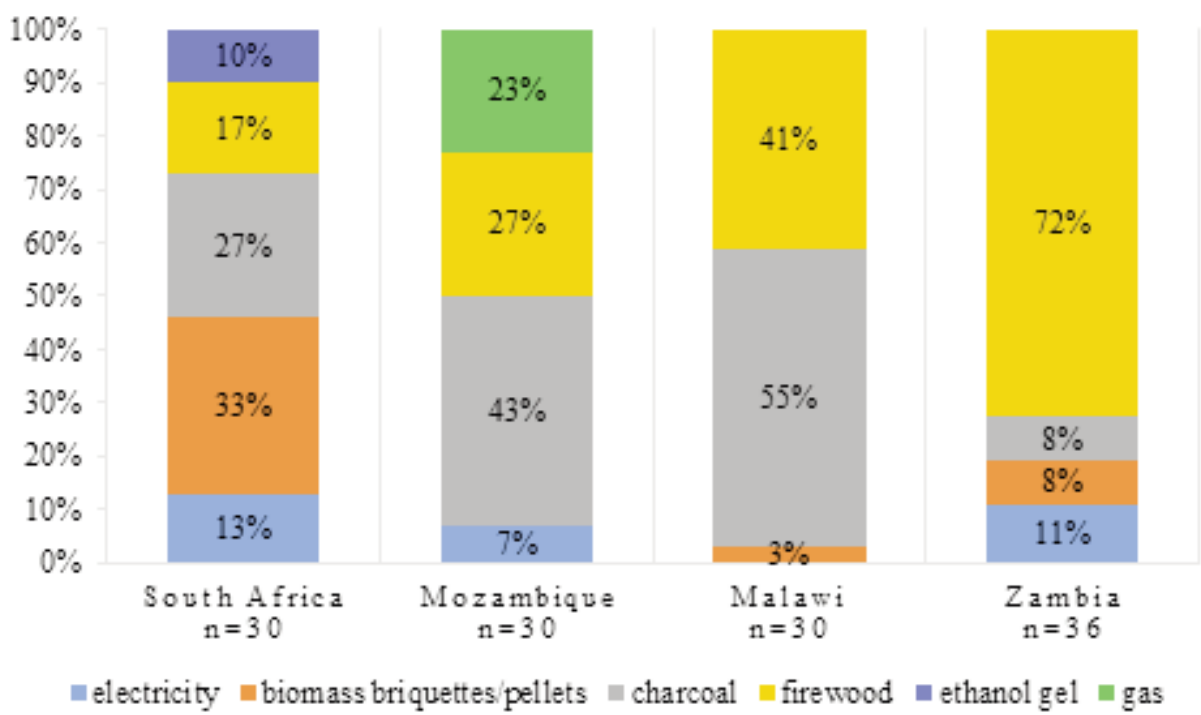

Figure 6: Main fuels currently used for cooking, where $\mathrm{n}=$ sample size.

Malawi commented that charcoal 'is easily found in our area' [Mal 12]. In Zambia, one respondent said that 'it [firewood] is the only one [fuel] available' [Zam 2], while another said: '[I] cannot afford to buy or produce charcoal, therefore use only wood' [Zam 5].

Modern fuels, including electricity and gas (in Mozambique), represented a relatively small proportion of cooking fuels. Only $13 \%$ of South African respondents used electricity as the main fuel for cooking. In Mozambique, $23 \%$ used gas, while only $7 \%$ used electricity. In Malawi, none used modern fuels for cooking, while in Zambia only $11 \%$ used electricity.

The fuel use profiles presented in Figure 6 are likely to be specific to the targeted population in this study, i.e., those without access to modern cooking fuels. The fuel use reported here does not represent the populations of the countries studied in general, but portrays an important sub-group of the popula- tion targeted through ICS interventions and initiatives. Furthermore, these energy profiles indicate the types of fuels used for cooking in the study sites concerning the type of cookstove present in the home.

Respondents were asked about their ideal fuels for cooking in addition to current fuel use, if all fuels were readily available. Figure 7 illustrates the aspirational fuel choices. In South Africa, $43 \%$ indicated that they would like to cook with electricity. One South African respondent selected electricity because 'it has multiple uses with lots of modern appliances' [SA 21], while another indicated that 'it is convenient and has multiples uses' [SA 22]. In Mozambique, $37 \%$ selected gas as their aspirational fuel of choice. One Mozambican respondent chose gas because 'it is accessible, clean and easy [to use]' [Moz 6], while another commented that cooking with gas is practical [Moz 5]. In Zambia, there was a high aspiration to cook with firewood (69\%). This 


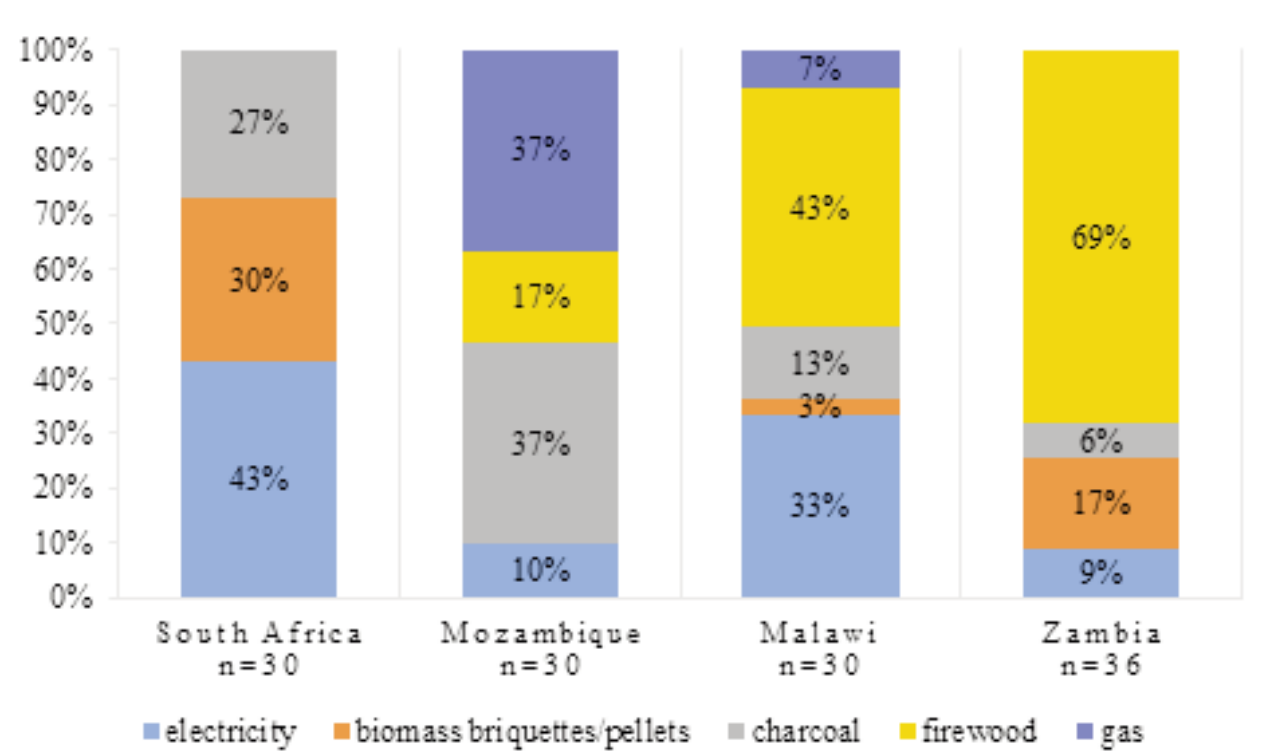

Figure 7: Aspirational fuels cooking, where $\mathrm{n}=$ sample size.

may be a realistic view because biomass is perceived to be an essential future fuel source (Owen et al., 2013) and access to modern fuels may not be physically accessible or affordable for these respondents.

\subsection{Cookstove preferences}

Respondents were asked about their first choice among available stoves for cooking, and to give reasons. Figure 8 shows that more than $69 \%$ in each of the four countries preferred cooking with an ICS. Some South African respondents with this preference cited the relative affordability of briquettes and charcoal compared with electricity as reasons, compounded by intermittent or unreliable electricity supply. For example, 'This household prefers [the] pellet stove [5 Star stove] because elec- tricity is expensive' [SA 7] and '(the) 5 Star stove because electricity is expensive and [I] get loadshedding, so not reliable' [SA 5].

In Mozambique, respondents preferred to cook with their ICSs because of their timesaving and versatility; economy; lightweight and durability; low charcoal and firewood consumption; low emissions; and cleanliness. One respondent preferred their Mbaula 'because it is very economical and portable' [Moz 3]. Another preferred it 'because of low charcoal consumption, low emissions, neatness and movability [Moz 11].

In Malawi, reasons included the availability of charcoal, affordability, reduced smoke, fuel reduction, fast heating, excellent heat retention, and portability. For example, the 'Kenyan Jiko uses charcoal which is locally available' [Mal 7], and the

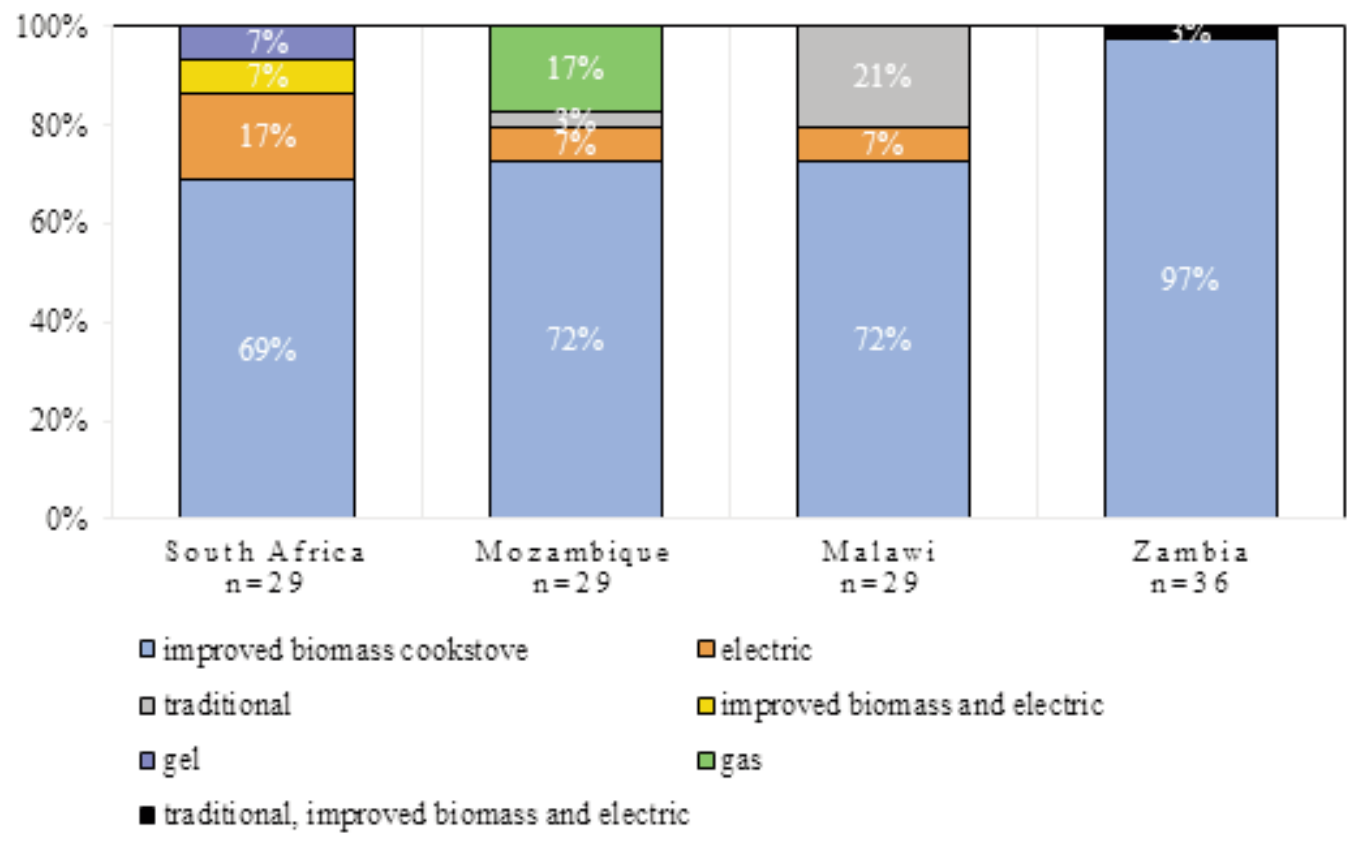

Figure 8: Cookstove preferences, where $n$ = sample size. 
Chitetezo Mbaula was preferred because it uses less wood when cooking, heat lasts a long time, and wood is free' [Mal 20].

Zambians who preferred cooking with an ICS cited similar reasons to those cited by some of the South African, Mozambican, Malawian respondents. These included using less wood with smaller logs, fast cooking, fuel saving, and less soot on pots. For example, the 3RL stove was preferred because it cooks faster, is clean and it uses less wood [Zam 10], while another preferred the 3RL stove as it uses less wood than the three-stone stove [Zam 13].

In South Africa and Zambia, no respondents selected their traditional biomass cookstove as their preferred cookstove. In Mozambique only one (4\%) preferred it, 'because it's easier to use' [Moz 27]. In Malawi, $17 \%$ preferred the traditional biomass stove: 'I use the three-stone because I only pay for the fuel. I am used to it and consider it to be the best' [Mal 14]; and 'we mostly use the three-stone as we don't have money for charcoal' [Mal 11].

Although, as Figure 1 showed, $60 \%$ of the respondents in South Africa had an electric stove in their home, only $17 \%$ preferred it to the Isitofu ICS. These households, all in KwaZulu-Natal, preferred using their electric stove because of convenience, fast cooking and safety.

Preference for the ICSs over traditional stoves showed a different pattern, with low fuel requirements, smoke reduction, cost savings and timesaving being their most desirable attributes. In Zambia, none selected the electric stove as their preference despite $22 \%$ of the respondents owning one. One Zambian respondent, who had possessed an electric stove for many years, indicated that the stove was never used and that the ICS was preferrred because of its time and cost savings [Zam 18].
Another respondent still preferred to use the ICS, although their electric stove was used daily for cooking, because of time saving and cleanliness [Zam 25]. This was not consistent with the notion of the energy ladder, or the assumption that people would automatically prefer their most 'modern' fuel or appliance. It also indicated that physical access to a modern energy carrier did not automatically translate into meaningful access to full or optimal utilisation of energy service.

Respondents were asked to list the main benefits of using an ICS. Figure 9 illustrates four of the most frequently mentioned benefits. In South Africa, $52 \%$ of respondents considered cost savings as one of the most important benefits, compared with $20 \%$ in Mozambique and 22\% in Malawi. The reported benefits are in line with a study conducted by the World Bank (2014). Increased efficiency and a concomitant fuel reduction resulted in increased cost savings.

It was found that $33 \%$ of respondents in Mozambique perceived fuel reduction as a main benefit. Respondents in Malawi and Zambia placed a higher value on fuel reduction and the ICS facilitating timesaving and a well-cooked meal. Fuel reduction was recognised by 30 and $42 \%$ of respondents in Malawi and Zambia respectively, while the speed with which meals are cooked was recognised by respectively 35 and $53 \%$ of respondents in Malawi and Zambia.

A range of problems and defects was also highlighted, in spite of a preference for cooking with ICSs. South African respondents reported difficulties with cleaning, post-use cooling and requirements for suitably cut wood. For example, 'the current ICS used by this household (Isitofu stove) makes the pots dirty and stays very hot. And big

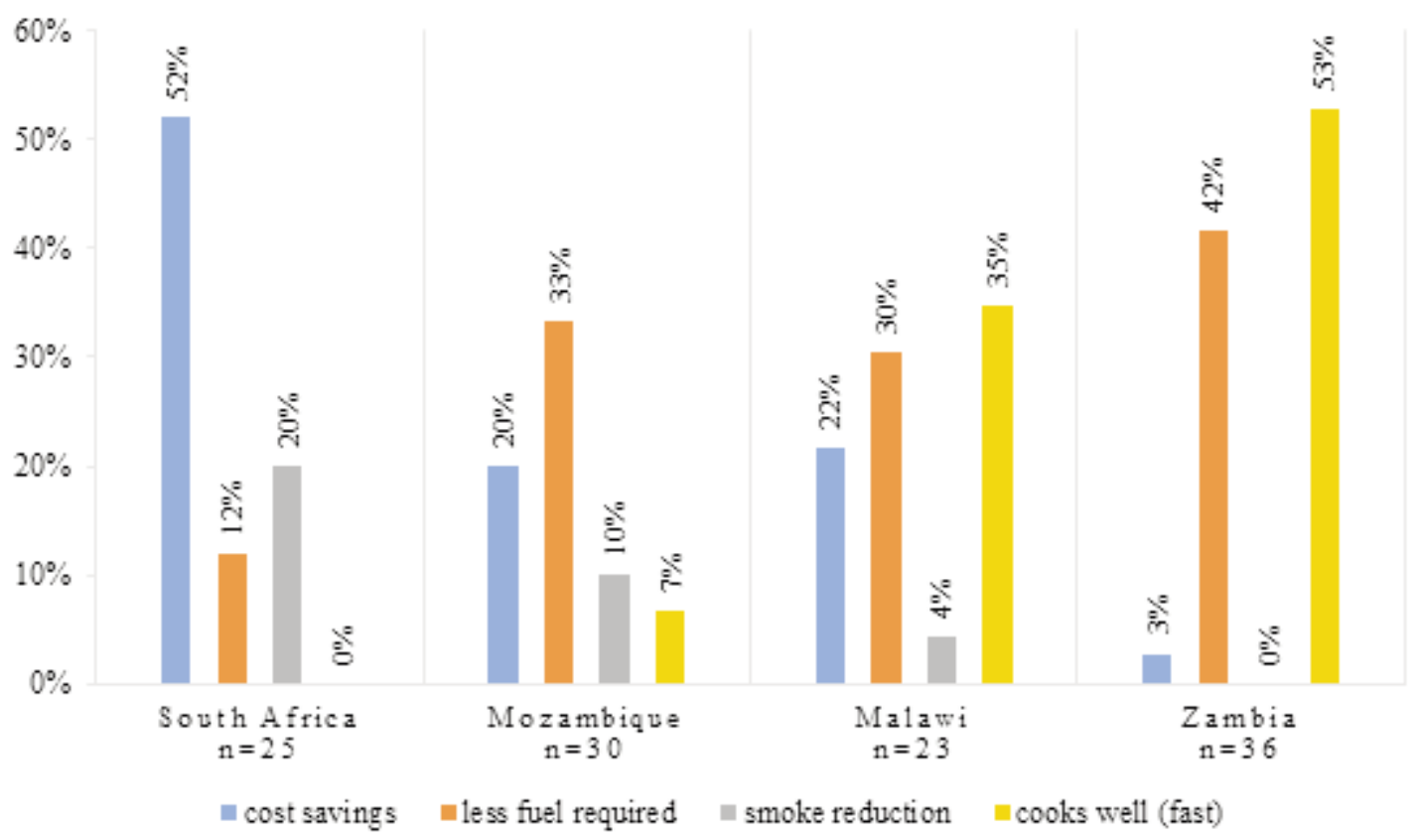

Figure 9: Reported benefits of cooking with ICSs, where $\mathbf{n}=$ sample size. 
wood needs to be chopped' [SA 21]; and 'when it gets hot it [the Isitofu stove] stays hot for a long time and you can't turn it off. Smoke is not good inside [the house], and the stove gets so hot you can't put it on the floor or table' [SA 27].

Among Mozambican respondents, difficulty in post-use cooling of the stove was also noted as a challenge. Other reported problems included slow heating, selective cooking environments and lack of durability . For example, "charcoal Mbaula [ICS] requires excessive care and cannot use water to cool it, rendering it unsafe to children' [Moz 9]; 'it takes time to start cooking compared with the electric stove' [Moz 10]; and 'the POCA [ICS] breaks easily, not very resistant or durable [Moz 12]. Problems were reported about durability, heat distribution and ventilation in Malawi. With reference to the Kenyan Jiko stove, 'the iron sheet outside the stove gets too hot', while another said they 'would prefer more air vents for better circulation' [Mal 13].

Respondents in Zambia, in addition to problems with durability, experienced problems with their 3RL Rocket stoves in terms of their short life (wearing of the inner lining; lack of strength and durability of the outer part of the stove) and the cracking of pots due to poor heat distribution. Specific views included: "[the] inner lining [is] not strong and wears away fast' [Zam 2]; 'outer part is not strong enough and started cracking' [Zam 6]; and '[the] outlet of the fire/heat is small and this leads to concentration of heat/fire of the centre of pots; which in turn cracks the pots' [Zam 12].

Durability of ICSs was a significant problem in three of the four study sites. Problems with the inner lining and wear and tear were identified, as well as breaking. The key drawbacks of the ICSs in Mozambique were operational and related to igniting the stove, cooking practice and height of the stove, whereas in South Africa the time involved in preparing the fuel was considered a major drawback. It is apparent that, depending on the stove distributed in each area, most stoves did not fully meet user requirements. This is not surprising considering the differences in implementation contexts in which the technology is required to operate. The results show that people are not passive recipients of technology, as they expressed varying levels of satisfaction or dissatisfaction depending on the actual utility derived from the use of a product, in this instance an 'improved' cookstove.

\section{Discussion}

Key benefits of cooking with ICSs include fuel savings, fuel reduction, smoke reduction, fast cooking, and cooking, which satisfies user preferences. Financial and timesaving drivers, as well as how well the cookstove facilitates the preparation of meals were perceived as key benefits by the majority of respondents. Fewer respondents also recog- nised the benefits of smoke reduction. As such, while health and environmental considerations are some of the main drivers of ICS programmes, these benefits may not be the primary reasons for deciding to acquire and continue to use an ICS. Crewe (1997) empasised that there are often divergent priorities between cookstove dissemination programmes and end-users. It is, therefore, important for ICSs to be responsive to the main requirements of end-user cooking and for these to be communicated. This is particularly important when using the market-based approach that is currently adopted by most cookstove initiatives, as people are unlikely to pay for a product that they do not perceive as indispensable.

Regional differences were apparent in the perceived benefits of ICSs in the four countries. The majority of respondents in South Africa perceived cost savings as the primary benefit compared with Zambia where fuel reduction was perceived as one of the main benefits, in particular when this relates to collection of fuel wood versus purchasing it. This supports the observations of Crewe (1997). It also reflects the highly diverging local contexts in which stoves are being promoted. For example, Malawi is characterised by high levels of biomass use and South Africa has relatively high electrification rates. These factors will affect not only the type of ICSs likely to be appropriate for implementation, but also the reference frame within which people adopt or purchase a stove. Local circumstances and developments need to be considered when promoting ICS initiatives.

Frequency and consistency of use is a vital aspect of the adoption of ICSs; more than $71 \%$ of respondents use their ICSs daily (Shankar et al., 2014). This figure may not be as accurate as the stove use-pattern data obtained from monitoring systems or wireless cookstoves sensors, but it does indicate how frequently households use their ICSs. Although this immediately appears to corroborate the selection of ICSs as many of the respondents' preferred stove, the high prevalence of stove-stacking somewhat alters the picture. For example, a significant percentage of respondents, most notably in Malawi and Zambia, still use their traditional cookstoves daily. The full health benefits of improved stoves with respect to reducing indoor air pollution cannot be fully realised by continuing to utilise conventional biomass stoves concurrently with improved biomass stoves. Questions can also be raised about the appropriateness of the provided stove if households continue with daily use of stoves other than their ICS. If a traditional stove provided space-heating, this would be an important consideration when designing ICS initiatives and might affect the promotion of a specific type of stove in a particular region. Similarly, if local culinary custom required a specific type of energy ser- 
vice, a market-based approach to ICS rollout would need to consider the type of meals cooked when identifying the most appropriate stove to be supplied. There is, therefore, no one size fits all.

End-users also reported a range of defects and challenges with ICSs, notwithstanding the majority of the respondents indicating a preference for cooking with them across the four countries. Some defects, such as the wear and tear (e.g., 3RL Rocket stoves in Zambia), indicate poor quality and durability, while difficulty with ignition and associated back problems (e.g. charcoal Mbaula stoves in Mozambique) reflect a deficit in user-friendliness. There were inherent problems with the stove design in respect with slow-heating of ICSs. Where good quality stoves may face a variety of challenges with regard to stove adoption, poor quality stoves that do not conform to minimum quality standards increase the challenge of uptake and sustained use. Poor quality cookstoves and stoves that are not user-friendly might, therefore, affect the actual usage patterns of ICS and could contribute to the continued use of other stoves, including traditional ones, despite the majority of respondents preferring to cook with their ICSs.

A market-based approach to ICSs may positively influence the sector as a whole through the 'free market'. This may result in a situation in which endusers can choose a stove that suits their energy needs and responds to the fuels available in the area, resulting in a real market situation.

Electric and improved biomass stoves was the most common cookstove combination in South Africa, while traditional biomass and ICS combinations were mostly found in Mozambique, Malawi and Zambia. The combinations of traditional biomass, improved biomass stoves and electric stoves were the most common stove-stacking combinations. The electric stove and ICS combination give rise to the question of whether ICS interventions should primarily target households that currently only use traditional open-fire and unimproved cookstoves or whether they should also target households that use modern energy services such as electricity as well as traditional cookstoves. This survey found that households with electric stoves did benefit from an ICS, primarily through saving costs. Furthermore, some households using electric and improved biomass stoves concurrently also possessed traditional biomass cookstoves; and ICSs may serve most of the functions previously served by the latter. Ruiz-Mercado and Masera (2015) highlighted that interventions that target mixed users were effective with indoor air pollution reduction and enhanced fuel savings, as users have the option of using both modern cooking technologies and cleaner fuels.

The respondents who continued to use traditional cookstoves in tandem with ICSs cited reasons such as the preparation of certain meals, spaceheating and water-heating. The prevalence of stove-stacking indicates that a single modern or improved stove does not necessarily serve all the functions of a traditional stove with regard to the preparation of specific meals and water- and spaceheating requirements. Ruiz-Mercado \& Masera (2015) advocated a broader range of ICS options, which take into account the broad spectrum of stove end-uses, tailored specifically for cooking and non-cooking stove purposes, such as water- and space-heating. This could include multi-purpose cookstoves that are designed to accommodate better water-heating or a greater variety of stoves that are suitable for specific purposes.

Biomass fuel sources such as charcoal and wood constitute a significant proportion of the cooking fuel-mix among the households sampled in all four countries. In contrast, cleaner energy options such as electricity, natural gas and ethanol gel constitute a relatively small proportion. The dominance of traditional solid biomass (i.e. firewood) and transitional solid biomass (i.e. charcoal and briquettes) could be attributed to a variety of factors, including a lack of regular access to modern energy services such as electricity or gas. Equally important in this regard is the affordability and reliability of these modern services. This can be seen in the cases where households with electric stoves preferred to cook with their ICS. These respondents corroborated the observations of Ruiz-Mercado \& Masera (2015) and Pachauri \& Spreng (2012) with respect to increased household energy security and resilience. The relative affordability and availability of biomass is also an important factor that could impact on fuel preferences. Urban charcoal and rural firewood are widely available in Malawi, Zambia and Mozambique, while electricity may be unaffordable and intermittent for respondents who do have access.

The ICSs use traditional firewood as well as transitional fuels, which enabled respondents to utilise solid biomass more efficiently. Therefore, as opposed to facilitating a transition to modern fuels, the cookstove interventions promoted the cleaner and more efficient combustion of traditional and transitional solid biomass.

\section{Conclusions}

This paper explored the experiences and preferences of users of improved biomass cookstoves, drawing on the findings of a small household survey in South Africa, Mozambique, Malawi and Zambia. The acquisition and adoption of these stoves did not result in a total replacement of traditional stoves by households. The factors that influenced initial adoption of a stove, such as cost of the technology and smoke reduction, differed from those influencing its sustained use. The latter cen- 
tred around saving fuel and costs, depending on whether fuel was bought or collected. Cookstove interventions, therefore, need to take into account factors that affect initial uptake of the technology alongside the factors that affect sustained use. Local circumstances and diverse sets of priorities that affect household decisions need to be considered when promoting or rolling out improved cookstove initiatives.

\section{Acknowledgements}

This work was made possible by the UK Department for International Development, the UK Department of Energy and Climate Change and the Engineering and Physical Sciences Research Council UK's joint grant EP/L002639/1: 'Understanding the barriers to the introduction and uptake of clean/improved cookstoves in SubSaharan Africa.'

\section{References}

Abdelnour, S. and Pemberton-Pigott, C. 2018. For cook and climate: Certify cookstoves in their contexts of use. Energy Research and Social Science 44:196198.

https://doi.org/10.1016/j.erss.2018.05.014

Atagher, P., Clifford, M., Jewitt, S. and Ray, C. 2017. Household perceptions of the value of improved cookstove (ICS), in Benue State, North Central Nigeria. Proceedings of the Conference on Strategies for Sustainable Energy Transitions in Urban SubSaharan Africa. 19-20 June 2017. SAMSET: Accra, Ghana

Bailis, R., Cowan, A., Berrueta, V. and Masera, O. 2009. Arresting the killer in the kitchen: the promises and pitfalls of commercializing improved cookstoves. World Development 37(10):1694-1705. https://doi.org/10.1016/j.worlddev.2009.03.004

Bardouille, P. 2012. From gap to opportunities: Business models for scaling up energy access. Washington, DC: International Finance Corporation.

Barnes, D.F. and Floor, W.M. 1996. Rural energy in developing country: a challenge for economic development. Annual Review of Energy and the Environment 21(1):497-530. https://doi.org/10.1146/annurev.energy.21.1.497

Barnes, D.F., Openshaw, K., Smith, K.R. and van der Plas, R. 1994. What makes people cook with improved biomass stoves ? A comparative international review of stove programmes. (World Bank Technical Paper Energy Series no. 242). Washington, DC: World Bank

Crewe, E. 1997. The silent traditions of developing cooks. In R.D. Grillo and R.L. Stirrat (eds), Discourses of development: Anthropological perspectives. London: Oxford University Press, pp. 5980.

Debbi, S., Elisa, P., Nigel, B., Dan, P. and Eva, R. 2014. Factors influencing household uptake of improved solid fuel stoves in low-and-middle-income countries: A qualitative systematic review. International Journal of Environmental Research and Public
Health 11(8):8228-8250.

https://doi.org/10.3390/ijerph110808228

Eckholm, E. 1975. The other energy crisis: Firewood Washington, DC: World Watch Institute.

Global Alliance for Clean Cookstoves. 2016a. Country profiles South Africa. Available: http://cleancookstoves.org/country-profiles/37-south-africa.html [2018, March 05]

Global Alliance for Clean Cookstoves. 2016b. Country profiles Malawi. Available: http://cleancookstoves.org/country-profiles/25malawi.html [2018, March 05].

Global Alliance for Clean Cookstoves. 2016c. Country profiles Zambia. Available: http://cleancookstoves.org/country-profiles/44-zambia.html [2018, March 05].

Global Alliance for Clean Cookstoves. 2017. Kerosene. Available: http://cleancookstoves.org/technologyand-fuels/fuels/ [2017, August 03].

Global Alliance for Clean Cookstoves. 2017. Market development. Available:

http://cleancookstoves.org/market-development/ [8, July 2017]

Gordon, J. and Hyman, J. 2012. The stoves are also stacked: Evaluating the energy ladder, cookstove swap-out programs, and social adoption preferences in the cookstove literature. Journal of Environmental Investing 3(1):17-41. https://doi.org/10.1016/S2213-2600(14)70168-7

Gordon, B., Bruce, G., Grigg, J., Hibberd, P., Kurmi, O. Lam, K et al. 2014. Respiritory risks from household air pollution in low and middle income countries. The LANCET Respiritory Medicine 2(10):823-860

Hiemstra-van der Horst, G. and Hovorka, A.J. 2008. Reassessing the 'energy ladder': Household energy use in Maun, Botswana. Energy Policy 36(9):33333344. https://doi.org/10.1016/j.enpol.2008.05.006

International Energy Agency. 2014. Africa Energy Outlook: A focus on energy prospects in SubSaharan Africa, IEA: Paris.

Jahan, S. 2003. Sustainable development and the millennium development goals the environment-poverty nexus in the southern african context. Proceedings of MDG Forum: Sustainable Development in Southern Africa: Mobilizing Partnerships and Capacity for Achieving MDGs. 2-4 July 2003. Johannesburg, South Africa.

Jewitt, S. and Raman, S. 2017. Energy poverty, institutional reform and challenges of sustainable development: The case of India. Progress in Development Studies 17(2):173-185 https://doi.org/10.1177/1464993416688837

Jewitt, S., Atagher, P., Clifford, M., Ray, C. and Sesan, T 2017. Energy and the environment in Sub-Saharan africa: household perceptions of improved cookstoves. In Shared research: Participatory and integrative approaches in researching African environments - Opportunities, challenges, actualities in natural and social sciences. 1-24.

Kaygusuz, K. 2011. Energy services and energy poverty 
for sustainable rural development. Renewable and Sustainable Energy Reviews 15(2):936-947. https://doi.org/10.1016/j.rser.2010.11.003

Kimemia, D., Vermaak, C., Pachauri., S and Rhodes, B. 2014. Burns, scalds and poisonings from household energy use in South Africa: Are the energy poor at greater risk? Energy for Sustainable Development 18: $1-8$. https://doi.org/10.7196/SAMJ.2017.v107i4.12436

Kimemia, D. and Van Niekerk, A. 2017. Energy poverty, shack fires and childhood burns. South African Medical Journal 107 (4): 289-291.

Kurmi, O., Lam, K., Ayres., J. 2012. Indoor air pollution and the lung in low and medium income countries. European Respiratory Journal 52 (3):1- 45

Lim, S.S., Vos, T., Flaxman, A.D., Danaei, G., Shibuya, K., Adair-Rohani, H., Amann, M., Anderson, H.R., et al. 2012. A comparative risk assessment of burden of disease and injury attributable to 67 risk factors and risk factor clusters in 21 regions, 1990-2010: A systematic analysis for the Global Burden of Disease Study 2010. The Lancet 380(9859):2224-2260. https://doi.org/10.1016/S0140-6736(12)61766-8

Makonese, T. and Meyer, J. 2018. Cooking sequences: The realistic utilization of fuel/stove combinations in standardised experiments. In 2018 International Conference on the Domestic Use of Energy (DUE). 1-6. IEEE.

Malla, S. and Timilsina, G.R. 2014. Household cooking fuel choice and adoption of improved cookstoves in developing countries a review. (The Policy Research Working Paper Series no. 6903). Washington, DC: World Bank

Masera, O.R. and Díaz, R. 2005. From cookstoves to cooking systems: The integrated program on sustainable household energy use in Mexico. Energy for Sustainable Development 9(1):25-36. https://doi.org/10.1016/S0973-0826(08)60480-9

Masera, O.R., Saatkamp, B.D. and Kammen, D.M. 2000. From linear fuel switching to multiple cooking strategies: A critique and alternative to the energy ladder model. World Development 28(12):20832103. https://doi.org/10.1016/S0305-750X(00)00076-0

Mills, E. 2016. Identifying and reducing the health and safety impacts of fuel-based lighting. Energy for Sustainable Development 30(1):39-50. https://doi.org/10.1016/j.esd.2015.11.002

Netherlands Development Organisation. 2017. Improving the market for cookstoves through market-based approaches. Available: http://www.snv.org/update/improving-market-cookstoves-through-market-based-approaches [8 July 2017].

Pachauri, S. and Spreng, D. 2012. Towards an integrative framework for energy transitions of households in developing countries. In . D. Spreng, T. Flüeler, D.L. GoldBlatt, and J. Minsh (eds), Tackling longterm global energy problems: The contribution of social science. Heidelberg: Springer.

Ray, C., Sesan, T., Clifford, M. And Jewitt, S. (forthcom- ing). Cleaning up our act: What constitutes an improved cookstove. Renewable and Sustainable Energy Review.

Rehfuess, E.A., Puzzolo, E., Stanistreet, D., Pope, D. and Bruce, N.G. 2014. Enablers and barriers to large-scale uptake of improved solid fuel stoves a systematic review. Environmental Health Perspectives 122(2):120-130. https://doi.org/10.1289/ehp.1306639

Rosenthal, E. 2009. By degrees: Third-world stove soot is target in climate fight. Available: http://www.nytimes.com/2009/04/16/science/earth/16 degrees.html [8 July 2017].

Ruiz-Mercado, I. and Masera, O. 2015. Patterns of stove use in the context of fuel-device stacking : rationale and implications. EcoHealth 12(1): 42-46. https://doi.org/10.1007/s10393-015-1009-4

Sesan, T. 2014. Global imperatives, local contingencies: An analysis of divergent priorities and dominant perspectives in stove development from the 1970s to date. Progress in Development Studies 1:3-20. https://doi.org/10.1177/1464993413504345

Shankar, A., Johnson, M., Kay, E., Pannu, R., Beltramo, T., Derby, E., Harrell, S. and Davis, C. 2014. Maximizing the benefits of improved cookstoves: Moving from acquisition to correct and consistent use. Global Health: Science and Practice 2(3):268 274. https://doi.org/10.9745/GHSP-D-14-00060

Simon, G.L. 2010. Mobilizing cookstoves for development: A dual adoption framework analysis of collaborative technology innovations in Western India. Environment and Planning A. 42(8):2011-2030. https://doi.org/10.1068/a42498

Smith, K.R. 1989. Dialectics of improved stoves. Economic and Political Weekly. 24(10):517-522.

Venkataraman, C., Sagar, A.D., Habib, G., Lam, N. and Smith, K.R. 2010. The Indian National Initiative for Advanced Biomass Cookstoves: The benefits of clean combustion. Energy for Sustainable Development. 14(2):63-72. https://doi.org/10.1016/j.esd.2010.04.005

Stockholm Environment Insitute. 2015. From theory to practice of change: Lessons from SNV's improved cookstoves and fuel projects in Cambodia, Kenya, Nepal and Rwanda. ( Working Paper no. 2015-09). Stockholm: Stockholm Environment Insitute.

Sustainable Energy for All. 2017. Universal adoption of clean cooking solutions. Available: http://www.se4all.org/hio_universal-adoption-ofclean-cooking-solutions [ $\overline{8}$ July 2017].

Tafadzwa, M. and Bradnum, C. 2017. Public participation in technological innovation: The case of the Tshulu stove development programme. Journal of Energy in Southern Africa. 28 (1):13-24. https://doi.org/10.17159/24133051/2017/v28i1a1379

Van Der Kroon, B., Brouwer, R. and Van Beukering, P.J.H. 2013. The energy ladder: theoretical myth or empirical truth? Results from a meta-analysis. Renewable and Sustainable Energy Reviews. 
20:504-513.

https://doi.org/10.1016/j.rser.2012.11.045

Westhoff, B. 1995. One of the oldest technologies in the world - from the open hearth to the microwave. In B. Westhoff and D. Germann, (Eds). Stove images: A documentation of improved and traditional stoves in Africa, Asia and Latin America. 18-19.

World Bank. 2011. Household cookstoves, environment, health, and climate change: A new look at an old problem. Washington, DC: World Bank.

World Bank. 2014. Clean and improved cooking in Sub-Saharan Africa. Washington DC: World Bank.

World Health Organisation. 2015. Household air pollution and health. Available: http://www.who.int/mediacentre/factsheets/fs292/en/ [27 August 2015]. 